\title{
Clinico-Pathologic Study of Salivary Gland Disorders at a Sub-Urban Nigerian Tertiary Hospital: A 5 Year Retrospective Review
}

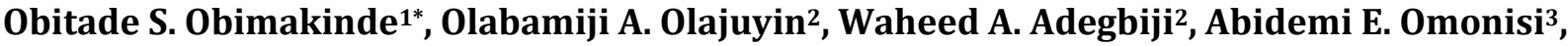 \\ John A. Omotayo ${ }^{3}$, Christopher O. Ibidun' ${ }^{1}$ \\ ${ }^{1}$ Department of Oral and Maxillofacial Surgery, Ekiti State University Teaching Hospital, Ado Ekiti, Nigeria \\ ${ }^{2}$ Department of Otorhinolaryngology, Ekiti State University Teaching Hospital, Ado Ekiti, Nigeria \\ ${ }^{3}$ Department of Anatomic Pathology, Ekiti State University Teaching Hospital, Ado Ekiti, Nigeria \\ Email: *tasky111@yahoo.com
}

How to cite this paper: Obimakinde, O.S., Olajuyin, O.A., Adegbiji, W.A., Omonisi, A.E., Omotayo, J.A. and Ibidun, C.O. (2019) Clinico-Pathologic Study of Salivary Gland Disorders at a Sub-Urban Nigerian Tertiary Hospital: A 5 Year Retrospective Review. International Journal of Otolaryngology and Head \& Neck Surgery, 8, 106-112.

https://doi.org/10.4236/ijohns.2019.83012

Received: March 6, 2019

Accepted: May 10, 2019

Published: May 13, 2019

Copyright ( 2019 by author(s) and Scientific Research Publishing Inc. This work is licensed under the Creative Commons Attribution International License (CC BY 4.0).

http://creativecommons.org/licenses/by/4.0/ (c) (i) Open Access

\begin{abstract}
Background: The spectrum of salivary gland lesions is wide and the relative incidence of neoplastic and non-neoplastic lesions is variable in different studies. Despite the relatively common nature of salivary gland disorders, there is dearth of literature on these lesions, especially in sub-Saharan Africa. We therefore embarked on this study to analyze the differential diagnosis of salivary gland lesions seen and managed at our institution. Methods: A retrospective review of salivary gland disorders that presented at our facility from January 2012 to December 2016 was done. Information on patients' demographic details, type and location of salivary gland lesion, histologic diagnosis and treatment were retrieved and analyzed with SPSS version 20. Result: A total of 65 patients were treated for salivary gland lesions of various types during the study period. The age of the patients ranged from 3 months to 68 years [mean $33.8 \pm 12.3$ ]. Neoplastic lesions $[\mathrm{n}=39,60.0 \%$ ] were the commonest followed by sialolithiasis [ $\mathrm{n}=14,21.5 \%$ ] while mucous retention/extravasation cysts accounted for $13.9 \%$ of the cases. Pleomorphic adenoma was the predominant tumor in this series [87.2\%] and the commonest site was the parotid gland [58.8\%]. On the contrary submandibular gland appeared to be the commonest site for sialolithiasis [57.1\%]. The majority of mucous retention/extravasation cysts occurred in the sublingual gland [55.5\%]. Conclusion: Neoplastic lesions remain the commonest salivary gland disorder and pleomorphic adenoma was the most prevalent. Sialolithiasis and mucous cysts are salivary gland lesions with equally wide disease spectrum.
\end{abstract}

\section{Keywords}

Salivary Gland, Lesion, Pleomorphic Adenoma, Sialolithiasis 


\section{Introduction}

Salivary gland tissues are distributed in the upper aerodigestive tract; the parotid, submandibular and sublingual being the major salivary glands [1]. The minor salivary glands are present in other sites such as lips, palate, tongue and oropharynx [1] [2]. Salivary gland diseases are relatively common and studies have shown that neoplasms account for the majority followed by obstructive lesions [2] [3] [4]. Major salivary gland lesions are often complicated by acute exacerbation due to infection and prompt management is therefore necessary to preserve the airway and other vital structures in the neck region.

Salivary gland disorders can be of inflammatory, bacterial, viral and neoplastic etiologies [4] [5] [6]. Obstructive sialadenitis (from stones or strictures) has been reported to account for approximately one-half of benign nonneoplastic salivary gland disorders [4]. Infections and inflammation of the salivary glands have a wide range of presentation ranging from acute recurrent to a painless chronic swelling [2] [6]. Epidemiological studies confirmed that neoplasms of the salivary glands are relatively rare and they constitute $6 \%$ of all head and neck tumors [7] [8] [9] [10]. Benign neoplasms typically present as painless, asymptomatic, slow-growing neck or parotid masses while malignant lesions are often more associated with pain and discomfort [10] [11] [12]. An organized approach to the evaluation of patients with salivary gland lesion improves the likelihood of correct diagnosis and appropriate treatment [4] [7].

Generally, there is dearth of published work on the differential diagnosis of neoplastic and non-neoplastic lesions of the salivary gland in sub-Saharan Africa. Moreover, there is no previously published data on this subject from our young institution which was established in 2009. This study was therefore designed to analyze the pattern and distribution of salivary gland lesions at our institution within a 5 year period.

\section{Materials and Method}

We conducted a retrospective survey of cases of salivary gland disorders that presented at our institution between January 2012 and December 2016. Patients' records were retrieved from the oral and maxillofacial surgery, otorhinolaryngology clinics and histopathology unit. Information obtained was reconciled and documented on individual proforma designed for each patient.

Data obtained include patients' demographic details, type of salivary gland lesion, histologic diagnosis and treatment received. Those with salivary gland tumors were further classified based on the 1991 World Health Organization [WHO] recommendation.

Data were summarized with cross tabulations and frequency tables. Descriptive statistic was done with SPSS Version 20.

\section{Result}

A total of 65 patients were treated for salivary gland lesions of various types 
during the study period. The age of the patients ranged from 3 months to 68 years [mean $33.8 \pm 12.3$ ]. The peak age incidence was between $3^{\text {rd }}$ and $4^{\text {th }}$ decade of life [20 - 40 years]. There was a slight male preponderance with male to female ratio of 1.2:1 [Table 1]. Thirty three patients [52.3\%] presented to the Oral and Maxillofacial surgery unit while the remaining [47.7\%] were seen at the Otorhinolaryngology clinic [Figure 1].

Salivary gland neoplasms $[\mathrm{n}=39,60.0 \%]$ were the commonest lesions in this study followed by sialolithiasis [21.5\%]. Mucous retention/extravasation cysts accounted for $13.9 \%$ [ $n=9$ ] of the cases [Figure 1]. Pleomorphic adenoma was the predominant tumor in this series [87.2\%] while Warthin's tumor and low grade mucoepidermoid carcinoma accounted for $7.8 \%$ and $5.1 \%$ respectively. Parotid gland was the commonest site for pleomorphic adenoma [ $\mathrm{n}=20,58.8 \%]$ followed by the palate $[\mathrm{n}=8,23.5 \%$ ] [Figure 2]. The two cases of mucoepidermoid carcinoma encountered occurred, one each in the parotid and submandibular glands. Warthin's tumor affected only the submandibular gland.

Majority of the sialoliths treated were of the submandibular gland/duct $[\mathrm{n}=8$, 57.1\%] followed by sublingual [21.4\%] while parotid gland was least affected [7.2\%] [Figure 3]. Eight patients [7 submandibular, 1 parotid] had Salivary gland excision under general anaesthesia due to intraglandular sialoliths. Five patients had calculus extraction by sublingual sialolithotomy via papillotomy and milking out under local anaesthesia.

Sublingual ranula $[\mathrm{n}=5,55.5 \%]$ constitute the majority of mucous retention/ extravasation cysts. Other mucous retention cysts were seen on the lower lip [n $=2]$, buccal mucosa $[\mathrm{n}=2]$. The 3 cases of sublingual dermoid cysts encountered in this series were excised under general anaesthesia.

The photomicrograph of one of the cases [pleomorphic adenoma] is shown in Figure 4.

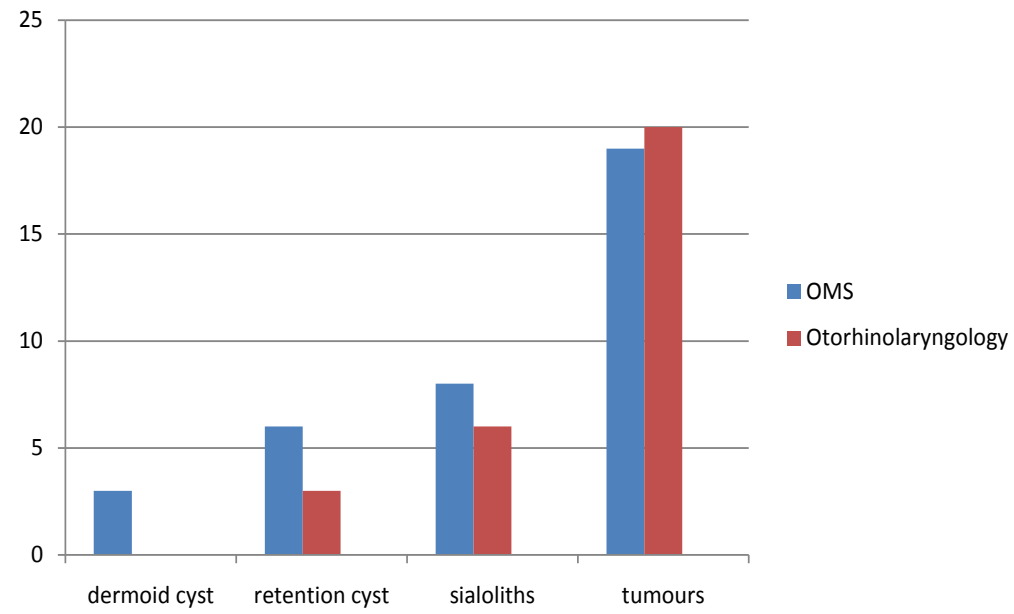

Figure 1. Salivary gland lesion and specialties involved in management. The figure showed the relative presentation of salivary gland pathologies to both Oral and Mexillofacial Surgery and Otorhinolaryngology units. Neoplastic lesions were predominant, followed by sialoliths. Dermoid cysts presented only to the Oral and Maxillofacial unit. 


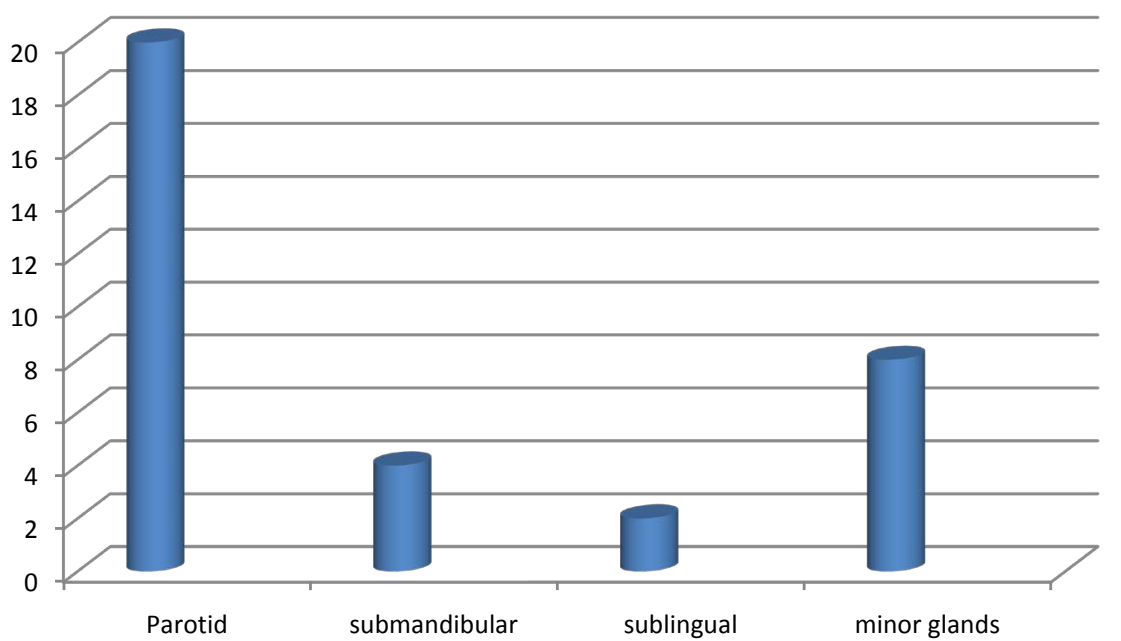

Figure 2. Site distribution of Pleomorphic adenoma. The figure revealed the site distribution of cases of pleomorphic adenoma seen in this study. The majority were found in the parotid gland followed by the minor salivary gland in the palate.

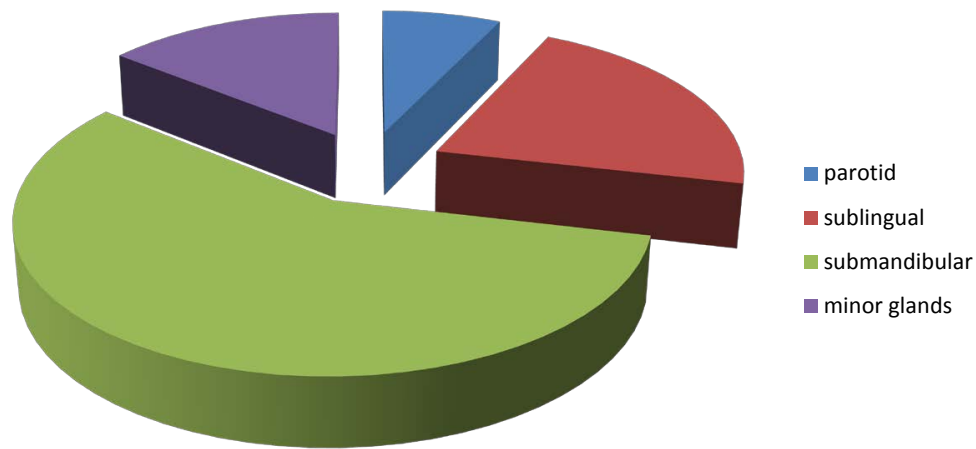

Figure 3. Site distribution of sialoliths. The chart shows that majority of sialoliths were found in the submandibular gland, followed by the sublingual gland. The parotid gland was least affected by salivary stones.

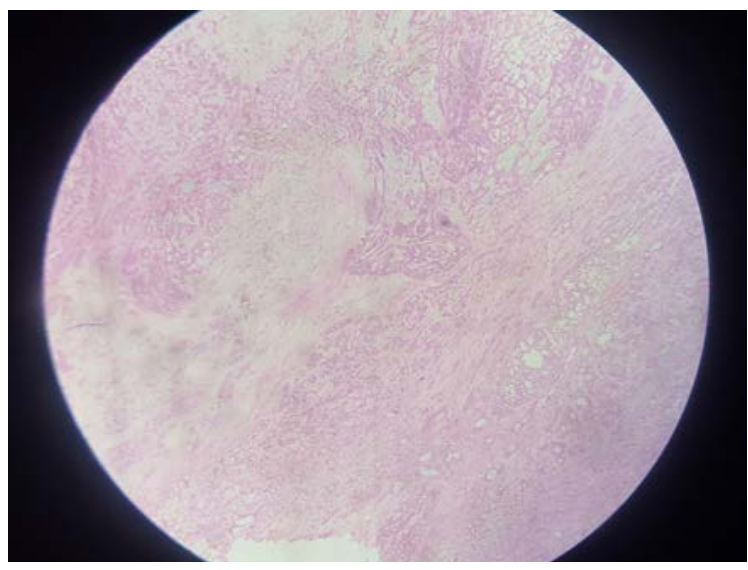

Figure 4. Photomicrograph of one of the cases [pleomorphic adenoma] treated. Photomicrograph of a tumor showing both epithelial component displaying glandular formation in areas andmyxoid mesenchyme stroma with benign fibroblastic proliferation representing the connective component. All showing benign features consistent with pleomorphic adenoma $(\mathrm{H} \& \mathrm{E}$ stain $\times 100)$. 
Table 1. Age and sex distribution of patients.

\begin{tabular}{cccc}
\hline Age range [years] & Male & Female & Total \\
\hline$<10$ & 3 & 1 & 4 \\
$10-19$ & 4 & 5 & 9 \\
$20-29$ & 7 & 7 & 14 \\
$30-39$ & 9 & 10 & 19 \\
$40-49$ & 11 & 5 & 16 \\
$>50$ & 2 & 1 & 3 \\
Total & 36 & 29 & 65 \\
\hline
\end{tabular}

\section{Discussion}

The incidence as well as the anatomical distribution of salivary gland lesions varies from one racial group and geographical location to the other [1] [4] [13]. However, studies from sub-Saharan Africa on differential diagnosis of salivary gland disorders are relatively sparse in the medical literature. Previous reports from this region only dealt with clinico-pathologic nature of salivary gland tumors while other pathologies such as sialolithiasis, mucous retention cysts and infections received negligible attention. This is the first appraisal of salivary gland lesions in our young institution which was founded in 2009, hence the relatively small nature of the data presented in this study. Furthermore, patients with benign, painless lesion hardly report for treatment in this part of the world unless there are associated symptoms.

The age range of $1^{\text {st }}$ to $6^{\text {th }}$ decade reported in this study is comparable to other reports [6] [8] [9] [10] [13]. Apart from malignant tumors which has predilection for advanced age, salivary gland diseases can occur at any age, this study and most authors agree that the peak age for benign disorders is between the $3^{\text {rd }}$ and $5^{\text {th }}$ decade [1] [4] [14] [15]. The higher male preponderance reported in this study agrees with some similar studies where there was a higher ratio of male subjects. On the contrary, Sando et al. [10] and Laishram et al. [11] reported higher female preponderance in their respective studies.

Pleomorphic adenoma was the commonest salivary tumor in this series. Although similar studies also reported that pleomorphic adenoma was the most prevalent salivary gland tumor, these include Williams et al. [6] 63.3\%, Otoh et al. [8] 44.3\%, Ladeinde et al. [9] 29.2\%, and Masanja et al. [15] 44.4\%. The incidence of pleomorphic adenoma in this study [87.2\%] was however higher than those other reports. However, the prevalence of malignant tumors in this study is comparatively lower than the reports from other authors [9] [11] [15] [16] [17]. The rather low proportion of malignant lesions in this series can be attributed to the fact that we currently do not have facility for radiation oncology treatment in our institution. Hence most patients prefer to have their surgery at centres where they can easily access chemo-radiation treatment.

In agreement with the literature, we found sialolithiasis as the major non- 
neoplastic salivary gland pathosis in this study [1] [2] [13]. The prevalence of salivary stones of $21.5 \%$ in this survey is comparable to findings from similar studies [13] [18]. Most cases of sialoliths are usually asymptomatic and patient hardly present to the health facility in this part of the world. Those reported in this study were symptomatic and pain was a major presenting complaint. In agreement with the study by Capaccio et al. [2], submandibular gland/duct was the commonest site of obstruction in this series.

Mucous retention and extravasation cyst was another salivary gland disorder reported in this study. Although mucous cyst is said to be commonest on the lower lip and affects minor salivary glands majorly [2] [5] [18] [19] [20], we however found the commonest site to be the floor of the mouth [66.7\%]. In a study of non-neoplastic salivary gland lesions, Gonzalez Guevara et al. [18] reported a $74 \%$ prevalence $[n=341]$ of mucous cyst. On the contrary, mucous cyst is not a common presentation in this environment due to their relatively small size and the fact that they are mostly asymptomatic.

\section{Conclusion}

Neoplastic lesions remain the commonest pathology afflicting salivary glands followed by sialoliths. Pleomorphic adenoma is the commonest neoplastic lesion and the parotid gland remains the major site of occurrence. Sialolith was the most common nonneoplastic salivary gland disorder in this study and the submandibular gland was majorly affected.

\section{Conflicts of Interest}

The authors declare no conflicts of interest regarding the publication of this paper.

\section{References}

[1] Al Sarraj, Y., Nair, S.C., Al Siraj, A. and AlShaye, M. (2015) Characteristics of Salivary Gland Tumors in the United Arab Emirates. Ecancer, 9, 583. https://doi.org/10.3332/ecancer.2015.583

[2] Capaccio, P., Torretta, S., Ottaviani, F., Sambataro, G. and Pignataro, L. (2007) Modern Management of Obstructive Salivary Diseases. ACTA Otorhinolaryngologica Italica, 27, 161-172.

[3] Wang, Y.-L., Zhu, Y.-X., Chen, T.-Z., Wang, Y., Sun, G.-H., Zhang, L., Huang, C.-P., Wang, Z.-Y., Shen, Q., Li, D.-S., Wu, Y. and Ji, Q.-H. (2012) Clinicopathologic Study of 1176 Salivary Gland Tumors in a Chinese Population: Experience of One Cancer Center 1997-2007. Acta Oto-Laryngologica, 132, 879-886.

[4] Wilson, K.F., Meuer, J.D. and Ward, P.D. (2014) Salivary Gland Disorders. American Family Physician, 89, 882-888.

[5] Rogers, J. and McCaffrey, T.V. (2010) Inflammatory Disorders of the Salivary Glands. In: Flint, P.W., Haughey, B.H., Lund, V.J., et al., Eds., Cummings Otolaryngology: Head and Neck Surgery. 5th Edition, Mosby, Maryland Heights, St. Louis, MO, 1151-1161.

[6] Williams, N.P., Boyd, D.L., Choy, L. and Hanchard, B. (2001) Salivary Gland Le- 
sions: A Jamaican Perspective. The West Indian Medical Journal, 50, 62-65.

[7] Subhashraj, K. (2008) Salivary Gland Tumors: A Single Institution Experience in India. British Journal of Oral and Maxillofacial Surgery, 46, 635-638.

https://doi.org/10.1016/j.bjoms.2008.03.020

[8] Otoh, E.C., Johnson, N.W., Olasoji, H., Danfillo, I.S. and Adeleke, O.A. (2005) Salivary Gland Neoplasms in Maiduguri, North-Eastern Nigeria. Oral Diseases, 11, 386-391. https://doi.org/10.1111/j.1601-0825.2005.01137.x

[9] Ladeinde, A.L., Adeyemo, W.L., Ogunlewe, M.O., Ajayi, O.F. and Omitola, O.G. (2007) Salivary Gland Tumors: A 15-Year Review at the Dental Centre Lagos University Teaching Hospital. African Journal of Medicine and Medical Sciences, 36, 299-304.

[10] Sando, Z., Fokouo, J.V., Mebada, A.O., NDjolo, F.D.A. and Oyono, J.L.E. (2016) Epidemiological and Histopathological Patterns of Salivary Gland Tumors in Cameroon. Pan African Medical Journal, 23, 66. https://doi.org/10.11604/pamj.2016.23.66.5105

[11] Laishram, R.S., Kumar, K.A., Pukhrambam, G.D., Laishram, S. and Debnath, K. (2013) Pattern of Salivary Gland Tumors in Manipur, India: A 10 Year Study. South Asian Journal of Cancer, 2, 250-253 https://doi.org/10.4103/2278-330X.119886

[12] Ezeanolue, B.C. (1999) Salivary Gland Neoplasms: A Descriptive Analysis of the Pattern Seen in Enugu. West African Journal of Medicine, 18, 179-182.

[13] Mohan, H., Tahlan, A., Mundi, I., Punia, R.P.S. and Dass, A. (2011) Non-Neoplastic Salivary Gland Lesions: A 15-Year Study. European Archives of Oto-Rhino-Laryngology, 268, 1187-1190. https://doi.org/10.1007/s00405-010-1460-3

[14] Vuhahula, E. (2004) Salivary Gland Tumors in Uganda: Clinicalpathological Study. African Health Sciences, 4, 15-23.

[15] Masanja, M.I., Kalyanyama, B.M. and Simon, E.N. (2003) Salivary Gland Tumours in Tanzania. East African Medical Journal, 80, 429-434. https://doi.org/10.4314/eamj.v80i8.8736

[16] Taghavi, N., Sargozaei, S., Mashhadiabbas, F., Akbarzadeh, A. and Kardouni, P. (2016) Salivary Gland Tumors: A 15-Year Report from Iran. Turkish Journal of Pathology, 32, 35-39. https://doi.org/10.5146/tjpath.2015.01336

[17] Ben Brahim, E., Ferchiou, M., Khayat, O., Zribi, S., M’Barek, C., Labbene, N., et al. (2010) Tumors of Salivary Glands: Anatomical Study and Clinical Epidemiology of a Series of 180 Cases. La Tunisie Médicale, 88, 240-244.

[18] González, G., Torres, T. and Martínez, M.G. (2005) Non-Neoplastic Enlargement of Salivary Glands: Clinico-Histologic Analysis. Revista Médica del Instituto Mexicano del Seguro Social, 43, 189-197.

[19] Martins-Filho, P.R., Santos, T.D.S., da Silva, H.F., Piva, M.R., de Souza Andrade, E.S. and da Silva, L.C.F. (2011) A Clinic-Pathologic Review of 138 Cases of Mucoceles in a Pediatric Population. Quintessence International, 42, 679-685.

[20] Ahad, A., Tandon, S., Lamba, A.K., Faraz, F., Anand, P. and Aleem, A. (2017) Diode Laser Assisted Excision and Low Level Laser Therapy in the Management of Mucus Extravasation Cysts: A Case Series. Journal of Laser in Medical Sciences, 8, 155-159. https://doi.org/10.15171/jlms.2017.28 